\title{
Growth patterns in mature desalination technologies and analogies with the energy field
}

\author{
Beatriz Mayor, Ph.D. (corresponding author) \\ International Institute for Applied Systems Analysis (IIASA) \\ Schlossplatz 1 \\ A-2361 Laxenburg, Austria \\ Tel: +432236807496 \\ mayor@iiasa.ac.at
}

\begin{abstract}
This article uses logistic growth curves to analyze and compare the historical dynamics in technology deployment and unit upscaling experimented by the three main desalination technologies: multi-effect distillation (MED), multi-flash distillation (MSF) and reverse osmosis (RO). It also explores whether these dynamics follow a number of patterns identified in another well studied technology family with increasing strategic importance for desalination, i.e. energy technologies. The analysis suggests that thermal technologies (MED and MSF) are in an advanced growth phase and approaching saturation, with deployment levels likely to peak before 2050. The logistic fit for RO lacks enough significance to derive meaningful future capacity projections. RO also shows a remarkably high average-to-maximum unit capacity ratio mirroring a modular and more granular nature. Meanwhile, the three technologies are found to meet a series of common patterns in the temporal and spatial sequence of deployment identified in energy technologies. Based on such patterns and technology natures, PV-RO hybrid systems may hold the highest potential to overcome the cost and energy footprint challenges of desalination in the future. This analysis can guide the integration of desalination into modelling frameworks intended to assess future technological scenarios to address water scarcity and sustainable development goals related challenges.
\end{abstract}

Key Words: desalination deployment; upscaling; energy; trends 


\section{Introduction}

Since the approval of the Sustainable Development Goals (SDG) Agenda in 2015, the scientific community has embarked on finding technological alternatives and combinations that help meet the SDG challenges with minimum undesired tradeoffs. Desalination is one of the technology options that can play an important role in achieving the water-related Sustainable Development Goal 6 (SDG6) and addressing future water scarcity challenges. It can provide additional water resources for human consumption and irrigation in water stressed areas [1], while also alleviating the pressure on fresh water resources in regions with water pollution or groundwater overexploitation problems. However, desalination technologies also face a number of sustainability and competitiveness challenges, and can have direct implications for other SDGs such as those focused on energy. These challenges include reducing and decarbonizing the high energy requirements of desalination compared to conventional water supply; sustainable disposal, reduction or recycling of hyper-saline waste brines; and reducing water inputs by increasing water recovery and performance ratios, all of which ultimately reflect on the final water production costs [2-5].

A number of initiatives and approaches have been developed to enhance hydrological or integrated modelling frameworks to incorporate a range of technological solutions, including desalination, with the aim of assessing various technology mix scenarios against a variety of sustainability criteria. Examples include work by Wada (2011)[6], Kim et al. (2016)[7], Hanasaki et al. (2016)[8], Caldera et al. (2016)[9] and Parkinson et al. (2018)[10]. These kind of exercises undertaken outside the desalination field benefit from an understanding of some basic and comparable parameters and trends of desalination technologies, as well as of how they relate to and interact with other technologies, in order to design scenarios of future technology development. Some of these parameters include technological deployment (installed capacity or installed units), costs, and some critical sustainability indicators such as energy or water consumption.

Similar exercises have been done extensively in the energy field. For instance, multiple assessments have explored the potential climate change benefits/impacts of alternative energy mix transitions [11], or technology innovation and deployment in certain energy technology clusters (i.e. renewable energies, low carbon energies)[12-14]. These exercises have benefitted from a number of studies exploring and quantitatively assessing the evolution patterns of energy technologies[15-17], providing useful insights for energy modelling and the energy industry.

From a cross-sectoral perspective, energy consumption required to produce high quality desalinated water (and the associated effects on water cost and carbon emissions) may be the main limitation of desalination as compared to other water supply alternatives. Despite the remarkable improvements achieved in the last decades - particularly in reverse osmosis with the energy recovery systems - there are thermodynamic limitations still presenting a boundary to future energy efficiency improvements [18,19] Parallel lines of innovation are increasingly looking at optimizing combinations of renewable energy-desalination systems to reduce this energy-for-water tradeoff. In this line, exploring commonalities in historical evolution patterns 
between energy and desalination technologies provides interesting insights to complement technical assessments of feasible technological combinations and their future prospects.

The present analysis is part of a broader assessment intended to describe and quantify historical dynamics of mature desalination technologies (MED, MSF and RO) across a series of dimensions, i.e., technology deployment, unit upscaling, costs, and water-energy indicators, which will serve as a basis for scenario modelling. The article focuses on the technology deployment and unit size aspects, which have a direct influence on capital costs due to economies of scale and learning processes, and pursues two objectives. First, to describe and quantify the temporal and spatial (location) dynamics of desalination technology deployment and unit upscaling. Second, to analyze whether these dynamics follow a number of common patterns identified in another well studied technology family that shows increasing strategic relevance for future desalination deployment, i.e. energy technologies. The article starts with an overview of the current technological and market status of desalination in section 2, providing the basis and logic for the selection of the three desalination technologies to be analyzed. Section 3 describes the methodological approach for various parts of the analysis. Section 4 presents the main results, followed by a discussion of the most prominent findings in section 5 . Finally, section 6 highlights the most important conclusions.

\section{Desalination technologies and their level of technological maturity}

Since the implementation of the first desalination projects in the late 1940s, desalination has moved forward in the technology innovation cycle. Several technological families and designs have emerged to reach different technological maturity and market deployment levels. Most desalination technologies are divided into two technological groups according to the principle applied for the desalination process. Technologies in the thermal family use thermal energy to heat and distil water. The main thermal technologies are multi-effect distillation (MED), multiflash distillation (MSF), and vapor compression distillation (VCD). During the 1960s, reverse osmosis (RO) emerged as the first of a second group of desalination technologies based on the use of membranes. Membrane-based technologies span reverse osmosis (RO), electrodialysis (ED), electrodialysis reversal (EDR), nanofiltration (NF), forward osmosis (FO), pulsed electrodialysis (PE), and captive deionization (CD). In addition to these major groups, other minor processes include solar desalination and freezing. The latter two processes have not yet achieved significant market success but may become valuable under special circumstances or with further development [5].

Within this technological array, MED, MSF and RO register the highest technical maturity and market deployment levels, accounting together for $92.7 \%$ of global installed desalination capacity with $8 \%, 11 \%$ and $73.7 \%$ shares respectively [20]. These three technologies are currently mature and established in the market [12], and have registered considerable investment and water production cost reductions, along with substantial energy efficiency improvements [21]. These characteristics have motivated their selection as the focus of this 
study. Here follows a brief description of the processes and their technological status, as well as a compilation of the main technological features summarized in table 1.

Multi-effect distillation (MED): MED is the oldest desalination method and is mainly applied for seawater desalination purposes. It uses the principle of alternated evaporation and condensation at reduced ambient pressure in a series of successive effects (or stages) to finally obtain a condensate of fresh water. The number of effects determines the volume of distilled water obtained and thus the performance ratio, but is limited by the total temperature range available and the minimum allowable temperature difference between consecutive effects [5]. MED plants require both thermal energy for the distillation process and electrical energy for the water pumping system, with typical value ranges of $45-230 \mathrm{MJ} / \mathrm{m}^{3}\left(12-19 \mathrm{kWhe} / \mathrm{m}^{3}\right.$ assuming power plant conversion efficiencies of $30 \%$ ) and $2-2,5 \mathrm{kWh} / \mathrm{m}^{3}$ respectively [22]. The first plant was constructed in 1945 in Preston, England, but the highest deployment is found in the Middle East, with $64 \%$ of global installed capacity [20]. Despite being the first commercialized desalination method, MED registered a slower market penetration than MSF due to significant salt precipitation (or scaling) problems and higher capital and operation costs [2]. Nevertheless, recent studies suggest that MED may replace MSF in future projects thanks to the significant improvements in energy and conversion performances [2]. Furthermore, it could even compete with seawater reverse osmosis (SWRO) for the treatment of highly polluted or saline raw waters [5].

Multistage Flash Distillation (MSF): MSF emerged shortly after MED as an alternative method for sea water desalination. The first plant was constructed in Casablanca, Morocco, in 1950, following a rapid expansion across the Middle East associated to thermal power plants [20]. The MSF process applies the principle of "flash distillation" by conducting previously heated water under high pressure through successive chambers operating at progressively lower pressures. As the water enters each chamber, it releases part of the pressure and rapidly boils, resulting in sudden evaporation or 'flashing'. The vapor generated by the flashing is condensed on heat exchanger tubes to produce a distilled water outflow [5]. MSF plants are usually bigger and operate at higher temperatures than MED, thus entailing higher energy consumption. Typical MSF thermal and electric energy requirements are in the order of 190-282 MJ/m $\mathrm{m}^{3}(16-23$ $\mathrm{kWhe} / \mathrm{m}^{3}$ ) and $2.5-5 \mathrm{kWh} / \mathrm{m}^{3}$ respectively.

A common characteristic of thermal plants is the need for additional water for cooling after the process. This water is usually obtained from the sea, which has historically determined their location to coastal areas and their application for sea water desalination purposes.

Reverse Osmosis (RO): RO, as the most common type of membrane technologies, applies external pressure to overcome the intrinsic osmotic pressure of seawater and reverse the natural flow direction across a membrane, leaving the dissolved salts behind [5]. This process requires only electric energy to power the pumps, with typical values ranging between $0.5-1.5 \mathrm{kWh} / \mathrm{m}^{3}$ for brackish water and $2.5-5 \mathrm{kWh} / \mathrm{m}^{3}$ for seawater depending on the feedwater salinity[22]. The

\footnotetext{
${ }^{1} \mathrm{kWhe}$ stands for kilowatt hour equivalent. The use of this unit is aimed at highlighting the difference between the equivalent electric requirements estimated through the conversion of thermal values, and the direct or real electric requirements.
} 
first plant was constructed in 1962 in Kuwait, followed by a quick expansion across the Middle East, North America, and the Mediterranean countries. RO overtook the installed capacity of both MED and MSF together, to finally reach a 73\% global market share in 2016 [20]. The success of RO lies in a number of factors: first, the lower energy requirements as compared to MSF and MED; second, technological improvements and membrane cost reductions allowed the reduction of capital and operation costs; and third, there is no need for cooling, allowing them to be used for inland brackish water treatment [21]. To date there is no other desalination technology that can compete with RO. The technology is expected to continue gaining market share, with the only significant competition posed by MED in countries with cheap oil supplies [20].

Table 1. Main technological features of MED, MSF and RO desalination technologies. Sources: $[5,20,22-25]$.

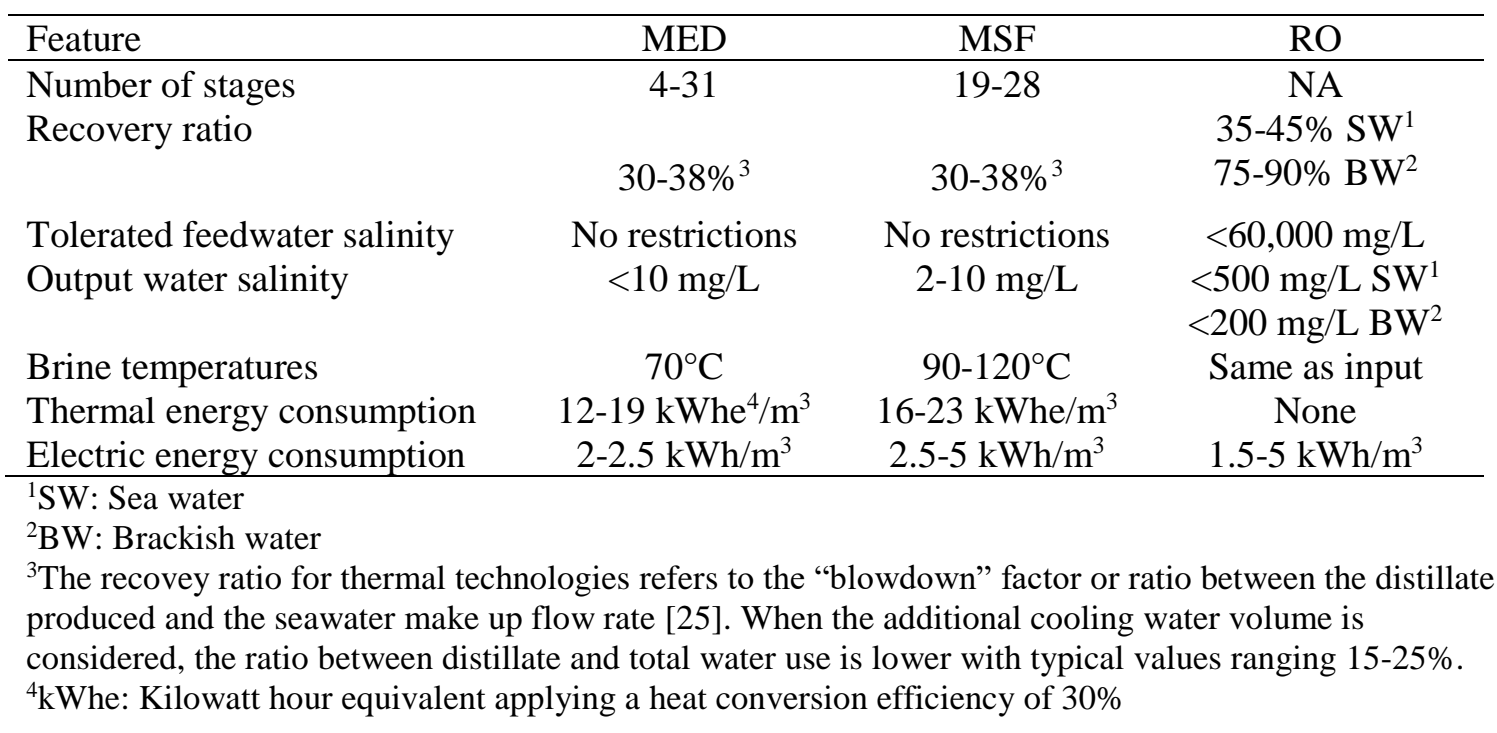

\section{Methods}

3.1 Data sources and treatment

Data for the analysis was obtained from the Global Water Intelligence's Desaldata database [26]. All available data for each target technology was checked for consistency, and a number of data assumptions and treatment steps were applied to ensure data homogeneity, consistency and usability.

The first assumption relates to the number of units per project. This work adopts the concept of unit used by the Global Water Alliance and the Desaldata database [26], where a unit is an independently functional system capable of producing the desired desalinate product. It can be composed of one or several stages and processes. Both thermal and reverse osmosis desalination projects can be comprised by a single unit, or by several units working in parallel. When information on the number of units per project was not available, a single unit project was assumed. In those cases where information on the installed capacity was missing, additional 
data in other sources were sough and, if not found, the projects were excluded from the analysis. The number of projects finally excluded amounted to less than $1 \%$ of the total projects.

Second, a pre-screening of the percentage of projects that are currently offline due to end-of-life or decomissioning was performed in order to assess the need for assumptions on plant decommissioning rates due to industry stock ageing. Resulting percentages of offline plants over the total industry stock by $2016^{2}$ were $7.5 \%$ for MED, $12.7 \%$ for MSF and $6.2 \%$ for RO. However, $80-90 \%$ of the cases were categorized as 'Presumed offline' based on the average plant life and the online date. Given the relatively low percentages strongly based on assumptions, the inclusion of a decommissioning component was not deemed necessary.

As a result, the analysis was built upon data from 1,306 MED, 829 MSF and 15,776 RO projects coming online in the periods 1945-2016, 1950-2016 and 1962-2016 respectively. The limitations resulting from the adopted assumptions are discussed in section 5.3.

\subsection{Logistic functions to describe technological growth patterns}

In the technology innovation literature, the use of S-shaped logistic functions is a common method for describing technological growth patterns [27,28]. Similarly, this method has been accepted and applied for trend extrapolation purposes when data cover more than half of the $S$ curve with high fit confidence levels [29-31]. A long record of historical evidence has shown that technologies go through a 3-stage process during their lifecycle: an initial period of slow growth, a sudden acceleration when the technology reaches high maturity and market confidence, and a final slow down until it reaches a technological deployment maximum (or saturation point) [15]. These three stages are well represented by an S-shape curve that, when fitted to the historical cumulative growth data of a given technology, allows the determination of a 3-parameter logistic function as described in equations 1 and 2.

$$
\begin{gathered}
\text { [1] } y=\frac{K}{1+e^{-b(t-t m)}} \\
\text { [2] } \Delta t=\log 81 \times b^{-1}
\end{gathered}
$$

where $K$ is the asymptote indicating the saturation level; $b$ is the diffusion rate indicating the steepness; $\overline{\Delta t}$ (delta $\mathrm{t}$ ) is the time period over which y grows from $10 \%$ to $90 \%$ of $K$; and $\mathrm{tm}$ is the inflection point at $K / 2$ where maximal growth is registered.

When fitting logistic functions to historical data, the obtained $\mathrm{K}$ and $\Delta \mathrm{T}$ parameters allow the characterization of the extents and rates of growth for different technologies and facilitates comparisons between them [16,32]. The suitability of this model for both types of analysis has been proven for a number of technologies [12,16,17].

The acceptability of the estimated logistic models was assessed based on two criteria: 1) fit quality, given by a $90 \%$ confidence level in obtained fits (adjusted $\mathrm{R}^{2} \geq 0.90$ ); 2) sufficient data coverage of the logistic curve, given by a threshold of $60 \%$ of the estimated asymptote parameter (K), as defined by Wilson (2012)[16]. In general, it is acknowledged within the

\footnotetext{
${ }^{2}$ Offline plants include the categories of 'Presumed offline', 'Offline (Decommissioned)' and 'Offline (Mothballed)' within the plant status indicator provided by the Desaldata database.
} 
technology innovation literature that acceptable logistic fits should cover at least half of the Scurve range $[30,33]$.

Growth function parameters were estimated using the "Logistic Substitution Model II" or 'LSM2' software. LSM2 was developed by the International Institute of Applied Systems Analysis (IIASA) and is freely available online. ${ }^{3}$

\subsection{Industrial growth analysis}

Industrial growth refers to the rapid and extensive growth in installed capacity or installed units experimented by technologies during their lifecycle [32]. Industrial growth marks the beginning of the market-uptake period in the technology's innovation cycle when the technology becomes widely adopted over time, in space, and between different social strata [28].

Industrial growth dynamics of desalination were described by fitting logistic functions to historical data on cumulative installed capacity and cumulative installed units over time on a yearly basis. The unit level was defined as each self-functioning plant, which can be installed either individually or in series in multi-unit projects.

To account for spatial (location) deployment, the analysis was done both at the global scale and disaggregating the data into initial (core), subsequent (rim) and late stage (periphery) adopting market regions, following the categorization by Wilson (2009)[28]. Deployment regions were singled out by plotting the evolution of cumulative installed units over time by geographical regions, and grouping them based on the timing of commercial uptake and upscaling into the aforementioned market stage categories. The resulting deployment regions for the three analyzed desalination technologies is presented in table 2 .

Table 2. Aggregation of geographical regions into deployment regions for MED, MSF and RO desalination technologies.

\begin{tabular}{lccc} 
& MED & MSF & RO \\
\cline { 2 - 4 } Market region & & Geographical regions & \\
\hline CORE & WEur + Nam & Mid. East & Mid. East + NAm \\
RIM & Mid East & WEur+Lam+EAsPac & WEur+ EAsPac \\
& & + NAm & \\
PERIPHERY & Lam+SAf+Sas+ & SAs+EE-CA+SAf & SAs+EE-CA+SAf \\
& EAsPac+EE-CA & & \\
\hline
\end{tabular}

Region acronyms: East Asia-Pacific (EAsPac), Eastern Europe-Central Asia (EE-CA), Latin AmericaCaribbean (Lam), Middle East-North Africa (Mid East), North America (Nam), Southern Asia (SAs), Sub-Saharan Africa (SAf) and Western Europe (WEur).

3.4 Unit upscaling analysis

Parallel to the growth in industrial capacity, technologies usually experience a unit upscaling process, or increase in unit size [32].

3 For further information on LSM2 and for downloads: http://www.iiasa.ac.at/Research/TNT/WEB/Software/LSM2/lsm2-index.html 
Unit upscaling dynamics were analyzed using logistic functions fitted to historical data on average capacity of unit additions and maximum capacity of the industry stock. It was estimated on a yearly basis by computing the average size of new units coming online every given year. The latter indicates the timing of the unit upscaling milestones (or the scale frontier) achieved by the industry. It was estimated by computing on a yearly basis the maximum unit capacity coming online every year and then estimating the envelope or maximum capacity registered to each given year.

Unit upscaling dynamics were also analyzed at the global scale and by market regions, using the aggregation described in the previous section. An additional sensitivity analysis was conducted for average capacity of unit additions at the global scale, since these curves would be used to build cost projection scenarios in later research stages. The analysis tested the variability in $\mathrm{K}$ and delta $\mathrm{T}$ when taking $100 \%, 90 \%, 75 \%$ and $50 \%$ of the samples and comparing the fits amongst alternative models (see supplementary material S1).

\section{Results}

4.1 Temporal and spatial growth trends

The results suggest that both thermal technologies, and especially MSF, are at an advanced stage in their technology growth curve and approaching saturation. Table 3 compiles the fit parameters and sensitivity measures for the industrial growth analysis by desalination technology and deployment region/global level.

Table 3. Industrial growth parameters for MED, MSF and RO. Numbers in grey indicate insufficient fit reliability according to the adopted criteria of minimum $\mathrm{R}^{2}=0.90$ and percentage of saturation (\% Sat) above $60 \%$.

\begin{tabular}{|c|c|c|c|c|c|c|c|c|c|c|c|c|}
\hline \multirow{3}{*}{$\begin{array}{l}\text { Technology } \\
\text { and } \\
\text { deployment } \\
\text { region }\end{array}$} & \multicolumn{6}{|c|}{ Cumulative capacity (CCap) } & \multicolumn{6}{|c|}{ Cumulative units (CUnits) } \\
\hline & \multirow{2}{*}{\begin{tabular}{|c|} 
Ref. \\
CCap \\
2016 \\
$\left(10^{6} \mathrm{~m}^{3} / \mathrm{d}\right)$
\end{tabular}} & \multicolumn{3}{|c|}{ Log fit parameters } & \multicolumn{2}{|c|}{ Sensitivity } & \multirow{2}{*}{\begin{tabular}{|c|} 
Ref. \\
CUnits \\
2016 \\
$\left(10^{3} \#\right)$ \\
\end{tabular}} & \multicolumn{3}{|c|}{ Log fit parameters } & \multicolumn{2}{|c|}{ Sensitivity } \\
\hline & & $\begin{array}{c}\mathrm{K} \\
\left(10^{6}\right. \\
\left.\mathrm{m}^{3} / \mathrm{d}\right)\end{array}$ & $\begin{array}{c}\mathrm{t}_{0} \\
\text { (year) }\end{array}$ & $\begin{array}{c}\Delta \mathrm{t} \\
\text { (year) }\end{array}$ & $\overline{\mathrm{R}^{2}}$ & Sat & & $\begin{array}{c}\mathrm{K} \\
\left(10^{3} \#\right)\end{array}$ & $\begin{array}{c}\mathrm{t}_{0} \\
\text { (year) }\end{array}$ & $\begin{array}{c}\Delta \mathrm{t} \\
\text { (year) }\end{array}$ & $\overline{\mathrm{R}^{2}}$ & $\begin{array}{l}\text { Sat } \\
(\%)\end{array}$ \\
\hline MED core & 0.71 & 0.8 & 1991 & 45 & 0.99 & 87 & 0.70 & 0.78 & 1980 & 58 & 0.98 & 90 \\
\hline MED rim & 4.36 & 6.3 & 2011 & 22 & 0.98 & 70 & 0.89 & 1,00 & 1993 & 51 & 0.98 & 89 \\
\hline MED per & 1.75 & 3.2 & 2014 & 59 & 0.99 & 55 & 0.56 & 0.61 & 1993 & 38 & 0.99 & 93 \\
\hline MED global & 6.82 & $10.3^{1}$ & 2011 & 39 & 0.98 & 65 & 2.16 & 2.39 & 1989 & 52 & 0.99 & 90 \\
\hline MSF core & 16.3 & 19.9 & 2000 & 45 & 0.98 & 81 & 0.96 & 0.99 & 1984 & 34 & $0.99^{2}$ & 98 \\
\hline MSF rim & 1.2 & 1.2 & 1973 & 40 & 0.94 & 100 & 0.54 & 0.54 & 1975 & 31 & $0.99^{2}$ & 100 \\
\hline MSF per & 0.09 & 0.09 & 1979 & 27 & $0.96^{3}$ & 99 & 0.06 & 0.06 & 1979 & 44 & $0.97^{2}$ & 97 \\
\hline MSF global & 17.5 & 21.1 & 1999 & 47 & 0.98 & 83 & 1.57 & 1.59 & 1981 & 34 & $0.99^{2}$ & 99 \\
\hline RO core & 29.10 & 100.5 & 2024 & 43 & 0.99 & 29 & 12.46 & 19.21 & 2009 & 47 & 0.99 & 65 \\
\hline RO rim & 22.13 & 38.5 & 2013 & 28 & 0.99 & 57 & 8.63 & 10.74 & 2005 & 34 & 0.99 & 80 \\
\hline RO per & 6.76 & 12.4 & 2014 & 25 & 0.99 & 54 & 3.72 & 7.54 & 2017 & 37 & 0.99 & 49 \\
\hline RO global & 57.99 & 147.2 & 2019 & 35 & 0.99 & 39 & 24.82 & 37.49 & 2009 & 43 & 0.99 & 66 \\
\hline
\end{tabular}

${ }^{1}$ A scenario $\mathrm{K}=$ Kcore + Krim + Kper is exogenously introduced to avoid implausibly large estimated $\mathrm{K}$ values. ${ }^{2}$ Fit adjusted to make logistic fit match real value in 2016 to avoid exceeding $100 \%$ saturation.

${ }^{3}$ Regression restricted to time period 1975-2016 to improve fit quality. 
The results for MED indicate an advanced growth stage, with higher saturation levels and longer deployment time periods $(\Delta \mathrm{t})$ in installed units than in installed capacity, both globally and across regions. This reveals a faster growth in number of units than in installed capacity driven by a relatively delayed process of unit upscaling, as observed in figure 1. Such an observation suggests that MED, as the first pioneer desalination technology entering the market, required long initial experimental stages (or 'formative phase') and the need to deploy a large number of small capacity units before unit upscaling was feasible. Meanwhile, the slightly higher difference in saturation levels amongst the rim, per, and global regions suggests that MED growth may continue at a slow pace featured by a small number of new units with rather large capacities.

MSF registers an even more advanced growth stage than MED. Saturation levels in the core region and global regions are above $80 \%$ in both installed capacity and installed units, reaching $100 \%$ in the rim and per regions. The deployment times $(\Delta t)$ are shorter for installed units than for installed capacity in this case, suggesting a relatively early and intense upscaling. Meanwhile, the cumulative and average capacity curves for both the industry and unit levels (figure 1) show that this upscaling are almost parallel. These results mirror the later entry of MSF technology in a market already opened by MED, where the possibility of a faster unit upscaling, together with other technical advantages allowing for lower capital costs, prompted a faster and more extensive deployment. An extrapolation of the growth curves for MED and MSF places the achievement of their industrial deployment peaks between 2030 and 2050, with installed capacities around 10.3 and 21 million cubic meters per day respectively (see figure 1).

In contrast to the observed situation for thermal technologies, the results reveal that RO is in at earlier stage in the technology growth curve. In fact, RO has not yet reached the $60 \%$ saturation threshold in the installed capacity curve (as shown by the grey colored entries in table 3 ), and thus the estimated model parameters have not enough significance to make projections. The installed units curve reveals a faster growth rate, with $60 \%$ saturation exceeded in the core, rim and global regions. When comparing the extent of deployment (K) amongst technologies, prospects for RO are much higher than for thermal technologies as could be expected. However, $\mathrm{K}$ values for RO should be only taken as a possible scenario given the high level of uncertainty to derive projections at relatively early growth stages.

Looking at the regional deployment patterns, MED and MSF markets have been mostly concentrated in the Middle East (core region for MSF and rim region for MED). MSF and RO follow the classic core-rim-periphery sequence with progressively lower Ks and $\Delta$ Ts indicating a slower but more pervasive deployment in the core region, which becomes less extensive in the rim and periphery[27]. MED presents a remarkable particularity in this respect, as deployment in the rim region reaches a significantly higher extent than in the core. These observations are further developed and contextualized in the discussion section 5.1. 


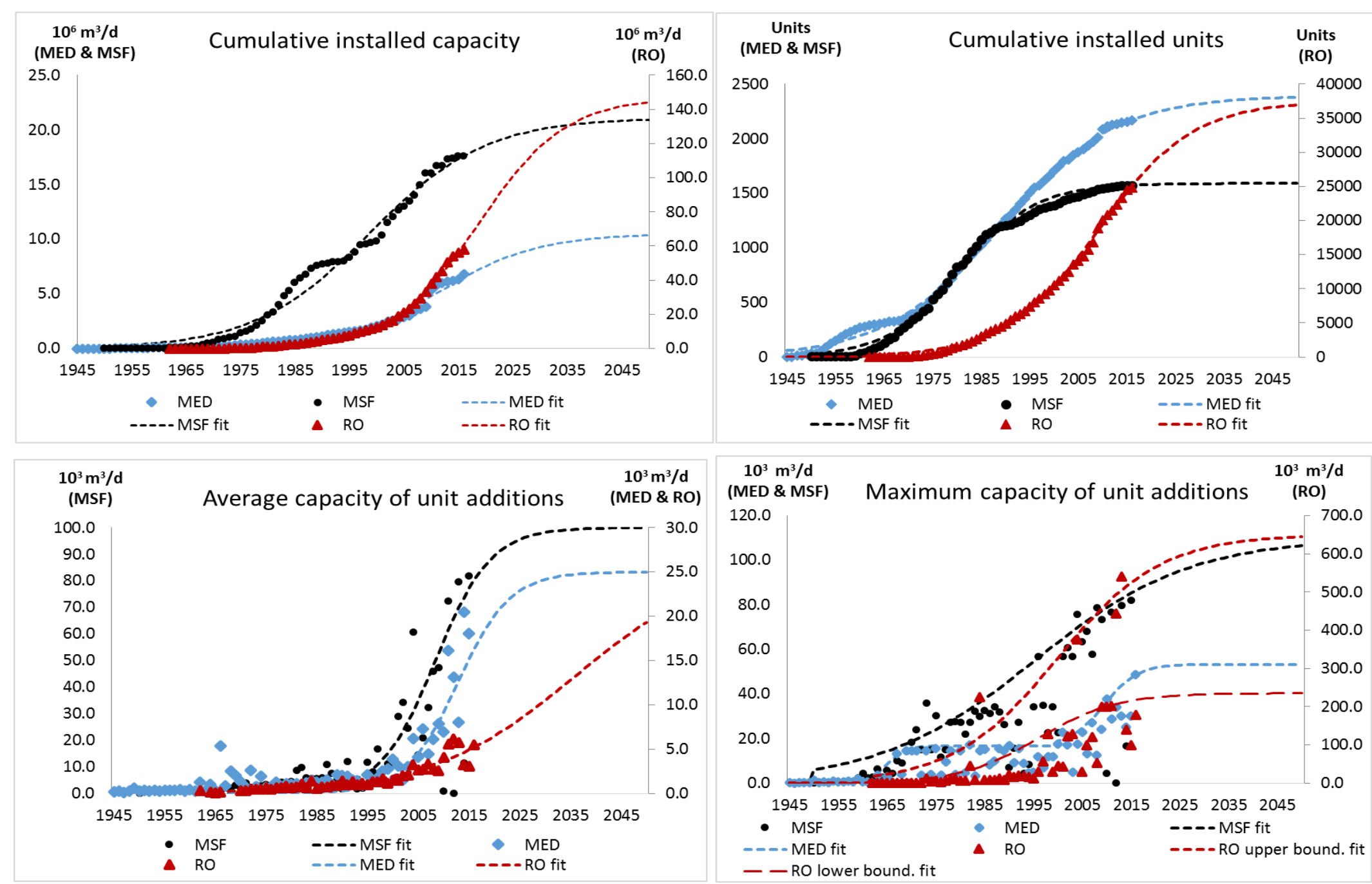

Fig 1. Graphical representation of global historical growth data and logistic fits at the industry and unit levels with trend extrapolations to 2050.

Historical data points are represented with a color and symbol code, with red triangles corresponding to RO, blue diamonds to MED and black circles to MSF data. Dashed lines show the modelled trends keeping the same color code (red for RO, blue for MED and back for MSF). Corresponding axes for each technology are indicated in the axis caption. 
The analysis of unit upscaling using logistic curves provided lower quality fits, which is to be expected given the high variability in yearly average capacities and dependence upon the number and characteristics of the projects (presence of possible outliers). Nevertheless, several strategies were adopted to improve the accuracy of the results and account for uncertainty. First, a diagnosis on a case by case basis was done to identify the different types of sources of uncertainty in the irregular fits and develop a consistent set of sensitivity analyses and strategies to address them. The four different types of identified uncertainty sources and the strategies and criteria applied to each type are described in detail in supplementary material S2. Second, a specific sensitivity analysis was performed to assess the uncertainty in average capacity of unit additions fits in the global region. The results showed variabilities in $\Delta \mathrm{t}$ below $0.83 \%, 0.04 \%$ and $1.51 \%$ for MED, MSF and RO respectively, and an exponential trend in $\mathrm{K}$ values towards the original value for RO, and thus considered acceptable. A detailed description of the analysis is provided in supplementary material S1. Table 4 shows the resulting parameters for average and maximum unit capacities.

Table 4. Unit upscaling parameters for MED, MSF and RO. Numbers in grey indicate insufficient fit reliability according to the adopted criteria of minimum $\mathrm{R}^{2}=0.90$ and percentage of saturation (\% Sat) above $60 \%$. An indication of the case type (T1-4) is provided next to the $\mathrm{R}^{2}$ for the cases with high uncertainty. A brief explanation of the case types is provided as table footnotes. Further detail can be found in supplementary material $\mathrm{S} 2$.

\begin{tabular}{|c|c|c|c|c|c|c|c|c|c|c|c|c|}
\hline \multirow{3}{*}{$\begin{array}{l}\text { Technology } \\
\text { Region }\end{array}$} & \multicolumn{6}{|c|}{ Average capacity of unit additions (Avcap) } & \multicolumn{6}{|c|}{ Maximum capacity of industry stock (Maxcap) } \\
\hline & \multirow{2}{*}{$\begin{array}{c}\text { Ref. } \\
\text { Avcap } \\
2012-16 \\
10^{3} \mathrm{~m}^{3} / \mathrm{d}\end{array}$} & \multicolumn{3}{|c|}{ Log fit parameters } & \multicolumn{2}{|c|}{ Sensitivity } & \multirow{2}{*}{$\begin{array}{c}\text { Ref. } \\
\text { Maxcap } \\
2016 \\
10^{3} \mathrm{~m}^{3} / \mathrm{d}\end{array}$} & \multicolumn{3}{|c|}{ Log fit parameters } & \multicolumn{2}{|c|}{ Sensitivity } \\
\hline & & $\begin{array}{c}\mathrm{K} \\
10^{3} \mathrm{~m}^{3} / \mathrm{d}\end{array}$ & $\begin{array}{c}t_{0} \\
\text { year }\end{array}$ & $\begin{array}{c}\Delta \mathrm{t} \\
\text { years }\end{array}$ & $\begin{array}{c}\mathrm{R}^{2} \text {, case } \\
\text { type }\end{array}$ & Sat & & $\begin{array}{c}\mathrm{K} \\
10^{3} \mathrm{~m}^{3} / \mathrm{d}\end{array}$ & $\begin{array}{c}\mathrm{t}_{0} \\
\text { year }\end{array}$ & $\begin{array}{c}\Delta \mathrm{t} \\
\text { years }\end{array}$ & $\begin{array}{c}\mathrm{R}^{2} \text {, case } \\
\text { type }\end{array}$ & $\begin{array}{c}\text { Sat } \\
\%\end{array}$ \\
\hline MED core & 1.7 & 2.3 & 1985 & & T1 & 100 & 17.5 & & & & & 38 \\
\hline MED & 1 & & & & & 54 & 4 & & & & & 81 \\
\hline \multirow[t]{3}{*}{ MED per } & 14.7 & 22.0 & 2011 & 19 & $0.74, \mathrm{~T} 2$ & 66 & 25.0 & 31. & 19 & 73 & 0.9 & 79 \\
\hline & & & & & & & & 16. & & 8 & & 100 \\
\hline & & & & & & & & 31. & 19 & & 0 . & 79 \\
\hline \multirow{3}{*}{$\begin{array}{r}\text { MED global } \\
\text { F1 } \\
\text { F2 } \\
\end{array}$} & 16.0 & 22.0 & 2012 & 21 & 0.81 & 72 & 48.6 & 54.0 & 2003 & 23 & $0.85, \mathrm{~T} 3$ & 91 \\
\hline & & & & & & & & 16.7 & & 9 & 0.5 & 100 \\
\hline & & & & & & & & 36.6 & 20 & & 0. & 85 \\
\hline MSF core & 80.0 & 110.0 & 2008 & 29 & & 78 & 81 & 110.0 & 19 & 6 & {$[2$} & 75 \\
\hline MSF rim & 9.0 & & & & No f & & 36 & 36.0 & 1970 & 12 & & 100 \\
\hline MSF per & 0.1 & & & & No fit,T1 & & 15 & 16.0 & 19 & 4 & & 95 \\
\hline MSF global & 80.0 & 100.0 & 2008 & 24 & 0.87 & 82 & 81 & 110.0 & 19 & . & & 74 \\
\hline \multirow[t]{2}{*}{ RO core } & 4.4 & 28.0 & 2040 & 70 & $0.95, \mathrm{~T} 2$ & 15 & 540 & 641.6 & 20021 & 32 & & 84 \\
\hline & & & & & & & 201.6 & 226.6 & 99 & 30 & & 89 \\
\hline \multirow{2}{*}{ RO rim } & 6.5 & 18.5 & 2024 & 49 & $0.87, \mathrm{~T} 4$ & 61 & 444.0 & 600.0 & 2010 & 17 & $0.94, \mathrm{~T} 4$ & 74 \\
\hline & & & & & & & & & & & & 48 \\
\hline & 2.9 & 11 & 20 & 75 & 0. & 36 & 100.0 & 103.7 & 2002 & 10 & 0.99 & 96 \\
\hline \multirow{2}{*}{ RO global } & 4.7 & 26.7 & 2036 & 63 & 0.84 & 15 & 540.0 & 641.6 & 2000 & 17 & $0.99, \mathrm{~T} 4$ & 84 \\
\hline & & & & & & & 201.6 & 235.2 & 1996 & 35 & $0.99, \mathrm{~T} 4$ & 85 \\
\hline
\end{tabular}

T1: Noisy data providing very poor or no fit.

T2: Implausibly high $\mathrm{K}$ values requiring adoption of an exogenous scenario.

T3: Multiple phase fits. Envelope fit and fits for phase 1 (F1) and phase 2 (F2) are provided.

T4: Presence of clear outliers shaping a different trend. Envelope fits with outliers (F1) and without outliers (F2) are provided.

Despite the lower accuracy of these results, some conclusions are possible. Looking at the average capacity in thermal technologies, MED saturates at lower K values than MSF, with highest averages reported in the Middle East region (core for MSF and rim for MED). This is coherent with the longer formative phase and 
relatively late unit upscaling process previously observed for MED. The unit size in this technology may have been limited by the thermal energy consumption, important scale formation problems (excessive precipitation of salts obstructing the system) and the increasing competition from MSF [5] (Arnaldos, personal communication). The remarkable average unit upscaling registered in the last decade mirrors a series of technical improvements and efficiency gains [2]. The same situation is observed at the capacity frontier. MSF, in turn, shows a faster and steeper upscaling phase that occurred almost simultaneously at the average and maximum capacity levels (see figure 1), as reflected by their similar $\mathrm{K}$ values. This difference is particularly pronounced in the core region (Middle East). Such phenomenon may have been facilitated by a simpler design, less vulnerability to scale formation, and the association to thermal power plants [5], which enabled early upscaling experiments at the technology frontier and a quick follow up by the bulk of the industry. Overall, the results suggest that both technologies are very close to saturation at both the average and maximum capacity levels.

In the case of RO, the unit upscaling process at the capacity frontier has been steeper than in thermal technologies, with particular influence by a few giant projects. In contrast, the average unit capacities have increased over time at a much lower pace and may remain around $20,000 \mathrm{~m}^{3} / \mathrm{d}$ per unit by 2050 . An observation that stands out from the table is the considerably higher difference between $\mathrm{K}$ values at the average and maximum capacity levels in RO compared to the thermal technologies. In order to contextualize these differences, table 5 compares the global average-to-maximum capacity ratios for the three desalination technologies with a sample of energy supply technologies analyzed by Wilson (2012)[16]. MSF and MED are in the upper ratio range. Particularly MSF has the highest ratio among all technologies, even above the least scalable energy technology, i.e. nuclear power. This mirrors the low scalability of the technology and the homogeneity of the market with a limited variety of applications. RO, in turn, is in the lower ratio range at the level of natural gas and hydropower turbines, which are much more scalable and granular technologies applied for a variety of different applications (gas turbines) and demand sizes (hydropower). Some additional reflection on the particular case of RO is elaborated in the discussion, section 5.1.

Table 5. Average/maximum unit capacity ratios for desalination technologies (global region) and some examples of energy supply technologies analyzed by Wilson (2012)[16].

\begin{tabular}{|c|c|c|c|c|c|c|c|c|}
\hline & \multicolumn{4}{|c|}{ Desalination technologies $\left(10^{3} \mathrm{~m}^{3} / \mathrm{d}\right)$} & \multicolumn{4}{|c|}{ Energy technologies (MW) } \\
\hline & \multicolumn{2}{|c|}{$\mathrm{RO}$} & \multirow[t]{2}{*}{ MSF } & \multirow[t]{2}{*}{ MED } & \multirow{2}{*}{$\begin{array}{c}\text { Coal } \\
\text { power }\end{array}$} & \multirow{2}{*}{$\begin{array}{c}\text { Natural } \\
\text { gas power }\end{array}$} & \multirow{2}{*}{$\begin{array}{c}\text { Nuclear } \\
\text { power }\end{array}$} & \multirow{2}{*}{$\begin{array}{l}\text { Hydro } \\
\text { power }\end{array}$} \\
\hline & F1 & F2 & & & & & & \\
\hline K for Av. capacity & \multicolumn{2}{|c|}{26.7} & 100.0 & 22.0 & 241 & 59 & 966 & 48 \\
\hline K for Max. capacity & 641.6 & 235.2 & 110.0 & 54.0 & 1,005 & 904 & 1,364 & 654 \\
\hline $\begin{array}{l}\text { Av/max } \\
\text { capacity K ratio }\end{array}$ & 0.05 & 0.13 & 0.91 & 0.46 & 0.24 & 0.07 & 0.71 & 0.07 \\
\hline
\end{tabular}

\section{Discussion}

\subsection{Technological dynamic patterns in desalination technologies}

The presented analysis allows the recognition in desalination technologies of some of the patterns depicted by Wilson et al. (2012)[16] for energy technologies. 
The first pattern states that technologies pass through three stages as they advance along the growth curve: 1) a 'formative phase' in which many small units are built with only moderate increases in unit capacity; 2) an 'upscaling phase' featuring large increases in unit capacities; and 3) a 'growth phase' with an extended deployment of large capacity units [16]. This pattern can be also recognized in the three desalination technologies, albeit with some slight pecularities. According to our results, MED has experienced a longer formative phase and relatively late unit upscaling process compared to MSF and RO, with the most remarkable increases registered in the last decade. An important factor explaining this delay are the scale formation problems, which increase with temperature and evaporation surface area. This results in higher costs and thus poses a limitation to the number of effects and overall plant size [2,5,20]. Meanwhile, larger plants required higher thermal energy inputs, which acted as a second limitation for unit upscaling [34]. MSF, in turn, is less prone to suffer scale formation problems [35], which — along with a simpler design and higher operational efficiency - provided a comparative advantage. As a result, MSF experienced a faster upscaling and a longer growth phase starting in the Middle East, with spillovers to North America and Western Europe (core and rim regions). Other factors promoting the success and permanence of MSF in the market included the shift toward better materials resulting in an expansion of plant lifespans and lower operation costs [20,25]. Overall, the competition with MSF and later with RO played as a third factor reducing the interest and thus experimentation and investment efforts (reduced learning) in MED. It is in the last decade that interest in MED has sprung up again due to the higher energy efficiency and suitability for coupling to solar thermal power $[2,3,20,22,36]$. In the case of RO, the technology has experienced a clear upscaling phase at the maximum capacity frontier, with high influences from a few exceptionally giant experiments, which may be close to giving way to the next 'growth phase'. The upscaling phase was not as clear at the average unit size level, which has increased at a rather slow and gradual pace. The strong differences between scales at the average and maximum capacity levels, further discussed below, suggest that the growth phase may play out in increasing installed capacity through a combination of small to medium unit size stand-alone plants and large multi-unit projects.

A second pattern refers to the spatial sequence of technology deployment, whereby technologies register longer delployment times in their core regions as a result of the need for a concurrent development of knowhow and both infrastructural and institutional settings [12,16]. Meanwhile, the rim and periphery benefit from knowledge spillovers enabling a deployment speed-up, albeit to a lesser extent due to the lack of accompanying contextual settings [12,28]. MSF and RO confirm the sequence core-rim-periphery with progressively lower $\mathrm{K}$ (extent of deployment) and $\Delta \mathrm{T}$ (deployment time) values, indicating a slower but more pervasive deployment in the core region, and a faster but less extensive one in the rim and periphery regions. However, MED deployment in the rim region reaches significantly higher extent than in the core. In this case, despite the fact that MED originated and was first implemented in Western Europe and North America - which constitute MED core regions - it quickly spread to the Middle East parallel to the emergence of MSF. Considered as rim (as a latter implementer partially benefitting from knowledge spill overs), the Middle East offered a series of facilitating conditions, i.e. extreme water stress and need for additional resources, high availability of cheap thermal energy and opportunities for technological combinations with thermal plants [20]. Altogether, this environment triggered a faster and more extensive industrial settlement and growth accompanied by more intensive technology innovation and learning processes. Meanwhile, in the initial core regions, the entry of RO in the market offering consistently lower energy requirements and investment costs (amongst other technical advantages) relegated MED to a rather marginal growth in specific cases, as reflected in the extremely high saturation levels reported in both installed capacity and installed units ( $87 \%$ and $90 \%$ respectively). 
A third pattern refers to the average/maximum capacity ratio, whereby big differences between average and maximum unit capacities are associated with technologies that vary greatly in market application and technological variability (i.e. gas turbines), but small differences are observed in technologies with homogeneous markets (i.e. nuclear power) [16].The shortest distance between the average and maximum unit capacity curves and closest $\mathrm{K}$ values were reported by MSF, which is mostly devoted for municipal drinking water supply (89\% of installed capacity) [26]. MED and RO, with larger differences between Ks at the average and maximum unit capacity levels, have more diverse market applications including municipal drinking water (50\% and 53.5\%), industrial uses (36\% and 34\%) and power stations $(12.16 \%$ and $6 \%)$ respectively and - in additionally in the case of RO - tourist facilities (2.5\%) and irrigation (2\%)[26]. The notably lower average/maximum capacity ratio in RO may also be influenced by other factors, such as the type of feed waters and the modularity. RO is applied to treat a higher range of water salinities as compared to MED and MSF, for which $89 \%$ and $90 \%$ of the installed capacity respectively operates with seawater. As of 2016, the share of RO installed capacity by feed water type was $44 \%$ seawater, $30 \%$ brackish water, $11 \%$ river water, and $6 \%$ pure water [26]. The feed water type is an essential parameter determining the structure (type of pretreatment), size, and cost of the installation [25,37], and thus could explain a higher level of heterogeneity in unit sizes. Meanwhile, RO allows for a modular configuration enabling the combination of several smaller units within a single project, i.e., up to 160 in the Rajasthan project in India or 400 in the Army project in Arizona [26]. This may have triggered a shift from the classical "vertical upscaling" trend by the construction of bigger units to a "horizontal upscaling" of projects by concatenating several smaller units, thus reducing the average unit capacity upscaling rate. An exception to this phenomenon would be the handful of giant industrial experiments, such as the Wonthaggi project in Australia $\left(440,000 \mathrm{~m}^{3} / \mathrm{d}\right)$ and the Soreq project in Israel $\left(540,000 \mathrm{~m}^{3} / \mathrm{d}\right)[26]$, which shape the upper boundary of the technology's capacity frontier. It is noteworthy, however, that single unit projects have dominated along the technology's history. As of 2016, single unit projects accounted for $80 \%$ of the whole industry stock (conveying $51 \%$ of installed capacity), followed by 2 -unit projects ( $11 \%$ of industry stock, conveying $9 \%$ of installed capacity), 3-unit projects $(3.5 \%$, conveying $6 \%)$ and projects with four or more units $(5.5 \%$, conveying $34 \%$ of installed capacity) [26], with an overall average of 1.6 units per project. However, when examining the period 20052016, the share diversifies to $60 \%, 22 \%, 7 \%$ and $11 \%$ of installed units and $15 \%, 12 \%, 8 \%$ and $65 \%$ of installed capacity for 1, 2, 3 and 4 or more unit projects respectively. According to these observations, the horizontal upscaling of projects may have started in 2005, along with a slight increase in average unit sizes. A possible trigger may be attributed to the role of spiral-wound flat-sheet membrane modules in module standardization and/or to the launch in 2004 of large diameter membranes allowing for larger units [38]. Other technological improvements included high pump pressures, energy recovery devices, and membrane cleaning systems [39]. A parallel observation is that in some of the exceptionally large projects built in the last decade, i.e., the aforementioned Australian examples, the quantum leap in capacity frontier came at the expense of an increase in specific capital costs due to diseconomies of scale (up to $6,0002010 \mathrm{US} \$ / \mathrm{m}^{3} / \mathrm{d}$ ). Such examples may push the trend towards the 'horizontal upscaling' rather than the 'vertical upscaling'.

\subsection{A prospective look into historical technology trends}

Looking at the growth phase with a prospective lens, the results of this study suggest that MED and especially MSF are currently very close to saturation and will probably achieve their industrial deployment peak before 2050. Several trend studies in the literature argue that thermal processes will remain in the market because they have been widely accepted in the Arabian Gulf area and because they provide waste heat recovery advantages when linked to thermal power plants $[5,20]$. The regional analysis undertaken 
highlights that growth will be mainly (and almost solely) concentrated in the Middle East, where these technologies are well rooted and the local market conditions provide important incentives for their deployment, i.e., addressing high water stress or due to wide availability of cheap thermal energy. These technologies are also more suitable — and may be preferred-for feed waters with extremely high salt concentrations, whereas RO finds physical limitations imposed by membrane tolerance [5]. Although some authors believe that MSF will continue to grow and may even have room for further learning processes $[2,25,40]$, the results in the present work support the hypothesis maintained by Ghaffour et al. (2013)[21] and Alvarado-Revilla (2015)[20] of MED overtaking MSF in number of installed units, but not in installed capacity. The main factors driving the shift back to MED as a preferred technology over MSF are identified in the literature as performance improvements and lower thermal energy and cooling requirements [2,20]. Reverse Osmosis, in turn, remains at an earlier stage in the technology growth curve and thus exhibits more room for further growth than do thermal technologies. The intense growth and rapid overcoming of thermal technologies experienced by RO has been explained as a result of lower investment and operation costs, facilitated by a number of factors: drastic reduction in energy requirements, thanks to the introduction of energy recovery systems; improvements in membrane technical parameters and water recovery ratios; new intake designs; and other technical and chemical improvements [21]. The magnitude and duration of this growth trend before it starts bending towards a sigmoidal shape may be determined by the strength of possible demand-pull and technology drivers. On the demand-pull side, exacerbating water scarcity or leveraging Sustainable Development Goals (SDG)-related policies may stimulate prolonged technology growth in suitable areas, although this growth is subject to mitigation of the energy trade-offs and success in the competition with other alternative water technologies. On the technology side, combining RO in hybrid schemes with other membrane-based technologies (FO, PRO, MD, CDI) is an emerging trend that may open the field to further technology improvements. However, experts highlight that there is no further margin for quantum leaps in technical improvements, energy efficiency, and cost reductions [21]. Regarding the desalination-energy technology links, the trends are shifting direction. The initial focus of coupling desalination units with thermal energy plants as a source of cooling water supply (water-for-energy focus) is moving towards coupling renewable energies to both thermal and RO desalination plants to reduce and decarbonize their energy footprint (energy-for-water approach). Thermal technologies - in particular, MED — seem to be more suitable for coupling with concentrated solar power [3,20,22,24]. This is consistent with the lumpy nature of both types of technologies. However, it also aggregates two technologies with high investment costs and slow learning rates, which will constrain the achievement of cost effectiveness and substantial market uptake. Trends for RO-renewable energy coupled systems point at wind and especially solar photovoltaic energy (PV) as the most promising system [3,9]. Both RO and PV are modular and relatively granular and scalable technologies, which may facilitate a faster market uptake and expansion. Meanwhile, PV has experienced remarkably high learning rates and cost reductions in the last two decades with prospects for further (although slower) reductions in the future [41]. As a result, the chances for this combination to become an economically feasible from a technology trends standpoint are higher. Altogether, renewable energy-desalination coupling may offer new opportunities to reduce the energy-water trade-offs while overcoming some of the environmental externalities identified as potential constraints for future desalination growth [42]. However, these options are still far from being cost competitive today [3].

As an additional note, some critical thinking on the feasibility limits of stimulated growth assumptions should be done when evaluating the capacity of reverse osmosis desalination to alleviate water scarcity. Considering scenarios where reverse osmosis is deployed to mitigate the water gap in water stressed regions 
by 2030 would require installed capacities of around 2,400 million $\mathrm{m}^{3} / \mathrm{d}$ [9]. This implies achieving in 11 years installed capacities that exceed 40 times the capacity deployed in over 50 years of technology history, which is simply impossible. Therefore, historical dynamics should be accounted for in technological scenario development, even when designing breakthrough scenarios.

\subsection{Limitations of the analysis}

212 There are limitations to this analysis related to data quality and methodological approach. Regarding data quality, the need to assume as 'single unit' those projects lacking data on the number of units may introduce some distortions in the average and maximum capacity estimations. Although individual checks were done for the larger scale projects, a complete check-up of all the projects was impossible due to the considerable number of missing data (4\% for MED, 6\% for MSF, and 26\% for RO). However, the non-checked projects were mostly small scale, so the assumption of a single unit was considered acceptable.

With regards to the methodological approach, the selection of S-curves to explain technological growth, and especially to extrapolate future values, has inherently a certain degree of uncertainty as will all trend forecasting models. However, S-curves have been widely used to describe natural growth patterns in different fields, including technology innovation [30]. A second methodological limitation relates to the selection of regions for the spatial diffusion analysis. The classification of geographical regions into the different 'diffusion regions' was done based on the timing of deployment. However, this involves the inclusion within each group of regions with very different characteristics, markets, and feed water sources, which may constitute another source of noise in the data reducing the quality of the fits.

Another possible limitation is the adoption of plant units instead of projects as a measure of experience along with installed capacity. This was done to account for the modularity aspect, which is one of the main differential characteristics among the analyzed technologies. An analogy could be made with studies analyzing deployment trends of wind energy, where individual windmills are taken as units instead of wind farms $[43,44]$.

A final possible limitation may come from the analysis of RO as a single technology without differentiating between sea water and brackish water desalination plants. Such differentiation would presumably lead to more homogeneous results in the unit upscaling analysis, since brackish water plant units tend to be smaller. precise estimations. This is considered as a possible follow up to this work.

\section{Conclusions}

This study has measured and discussed the historical trends in industrial deployment and unit upscaling of the three main desalination technologies and explored the similarities with patterns found in a closely connected and strategically important family, i.e., energy technologies.

The historical deployment of desalination technologies was found to follow a very clear logistic growth trend in installed capacity and, to a lesser extent, in the unit size. Thermal technologies are found to be well advanced in their growth curves and approaching saturation, with deployment peaks likely to occur before 2050. This may be explained by the lower competitiveness in costs and energy efficiency as compared to $\mathrm{RO}$, which has relegated the market for thermal technologies to the particular low-cost energy conditions of the Middle East. Meanwhile, marginal new market opportunities for MED may come from the coupling with concentration solar power. RO, in turn, reports an earlier stage in the growth curve and further room for 
future growth. However, the uncertainty in making future growth forecasts is higher, and thus an array of industrial growth scenarios may be possible driven by demand and technological factors. These could span from a strictly logistic trend, through to a more drastic demand pull driven increase. At the unit level, RO has a remarkably low average-to-maximum unit capacity ratio mirroring modularity and granularity. These two features shared with solar PV systems may act as facilitators to speed up market uptake and expansion of hybrid RO-PV systems. Furthermore, this could be prompted by the relatively high learning rates in solar PV that could help push down the systems cost in the midterm future. MED and MSF, in turn, have medium to high ratios closer to those of coal power plants or even nuclear power plants (the least scalable energy technology). This reflects the strong association between thermal desalination and power plants, as the latter present the primary historical application for thermal desalination. It also points at concentrated solar power as a natural partner for hybrid renewable energy-thermal desalination, although the horizon for economic competitiveness breakeven and market uptake lags considerably behind.

Overall, desalination technologies are found to follow several patterns similar to those of energy technologies in the temporal and spatial sequence of technology deployment. An exception is found in MED reaching further expansion and pervasiveness in its rim region (Middle East) than in the core region (Europe and North America), driven by the particularly favorable market conditions offered by the Middle East.

These findings provide important insights that should be taken into account by modelling frameworks integrating desalination as a possible solution to address water scarcity challenges and pathways to achieve SDG targets, and/or to optimize water-energy-land resource management. In particular, they can prevent excessively optimistic and unrealistic assumptions of future desalination capacity that overestimate or overemphasize the potential of desalination to alleviate water stress, which may promote water supply focused approaches to the problem undermining the water demand management side.

\section{Acknowledgements}

I would like to thank Dr. Arnulf Grubler, Director of the Transitions to New Technologies program at the International Institute of Applied Systems Analysis (IIASA), for his guidance and advice during the performance of this research. I am also grateful to my colleague Dr. Edward Byers, research scholar at IIASA, and Regina M. Buono, Non-resident Scholar at the Center for Energy Studies at Rice University's Baker Institute for Public Policy, for their support as proof readers and providing valuable comments to the final manuscript.

\section{References}

[1] M. Sarai Atab, A.J. Smallbone, A.P. Roskilly, An operational and economic study of a reverse osmosis desalination system for potable water and land irrigation, Desalination. 397 (2016) 174-184. doi:10.1016/j.desal.2016.06.020.

[2] T. Mezher, H. Fath, Z. Abbas, A. Khaled, Techno-economic assessment and environmental impacts of desalination technologies, Desalination. 266 (2011) 263-273. doi:10.1016/j.desal.2010.08.035.

[3] A.B. Pouyfaucon, L. García-Rodríguez, Solar thermal-powered desalination: A viable solution for a potential market, Desalination. (2018). doi:10.1016/j.desal.2017.12.025.

[4] M. Elimelech, W.A. Phillip, The Future of Seawater Desalination: Energy, Technology, and the Environment, Science. 333 (2011) 712-717. doi:10.1126/science.1200488. 
[5] A.D. Khawaji, I.K. Kutubkhanah, J.-M. Wie, Advances in seawater desalination technologies, Desalination. 221 (2008) 47-69. doi:10.1016/j.desal.2007.01.067.

[6] Y. Wada, L.P.H. van Beek, M.F.P. Bierkens, Modelling global water stress of the recent past: on the relative importance of trends in water demand and climate variability, Hydrology and Earth System Sciences. 15 (2011) 3785-3808. doi:10.5194/hess-15-3785-2011.

[7] S.H. Kim, M. Hejazi, L. Liu, K. Calvin, L. Clarke, J. Edmonds, P. Kyle, P. Patel, M. Wise, E. Davies, Balancing global water availability and use at basin scale in an integrated assessment model, Climatic Change. 136 (2016) 217-231. doi:10.1007/s10584-016-1604-6.

[8] N. Hanasaki, S. Yoshikawa, K. Kakinuma, S. Kanae, A seawater desalination scheme for global hydrological models, Hydrology and Earth System Sciences. 20 (2016) 4143-4157. doi:10.5194/hess-20-

[9] U. Caldera, D. Bogdanov, C. Breyer, Local cost of seawater RO desalination based on solar PV and wind energy: A global estimate, Desalination. 385 (2016) 207-216. doi:10.1016/j.desal.2016.02.004. [10] S. Parkinson, V. Krey, D. Huppmann, T. Kahil, D.L. McCollum, O. Fricko, E. Byers, M. Gidden, B. Mayor, Z. Khan, C. Raptis, N. Johnson, Y. Wada, N. Djilali, K. Riahi, Balancing clean water-climate change mitigation tradeoffs., International Institute for Applied Systems Analysis, 2018.

[11] GEA, Global Energy Assessment - Toward a Sustainable Future, Cambridge University Press, Cambridge, UK and New York, NY, USA and the International Institute for Applied Systems Analysis, Laxenburg, Austria, 2012. www.globalenergyassessment.org.

[12] A. Grübler, C. Wilson, eds., Energy technology innovation: learning from historical successes and failures, Cambridge University Press, New York, 2014.

[13] C. Wilson, A. Grubler, N. Bauer, V. Krey, K. Riahi, Future capacity growth of energy technologies: are scenarios consistent with historical evidence?, Climatic Change. 118 (2013) 381-395. doi:10.1007/s10584-012-0618-y.

[14] G.F. Nemet, A. Grubler, D.M. Kammen, Countercyclical energy and climate policy for the U.S.: Countercyclical energy and climate policy for the U.S., Wiley Interdisciplinary Reviews: Climate Change. 7 (2016) 5-12. doi:10.1002/wcc.369.

[15] A. Grübler, N. Nakićenović, D.G. Victor, Dynamics of energy technologies and global change, Energy Policy. 27 (1999) 247-280. doi:10.1016/S0301-4215(98)00067-6.

[16] C. Wilson, Up-scaling, formative phases, and learning in the historical diffusion of energy technologies, Energy Policy. 50 (2012) 81-94. doi:10.1016/j.enpol.2012.04.077.

[17] N. Bento, C. Wilson, Measuring the duration of formative phases for energy technologies, Environmental Innovation and Societal Transitions. 21 (2016) 95-112. doi:10.1016/j.eist.2016.04.004.

[18] A. Stillwell, M. Webber, Predicting the Specific Energy Consumption of Reverse Osmosis Desalination, Water. 8 (2016) 601. doi:10.3390/w8120601.

[19] G. Amy, N. Ghaffour, Z. Li, L. Francis, R.V. Linares, T. Missimer, S. Lattemann, Membrane-based seawater desalination: Present and future prospects, Desalination. 401 (2017) 16-21. doi:10.1016/j.desal.2016.10.002.

[20] F. Alvarado-Revilla, Desalination markets 2016: global perspective and opportunities for growth, Media Analytics, Oxford, 2015.

[21] N. Ghaffour, T.M. Missimer, G.L. Amy, Technical review and evaluation of the economics of water desalination: Current and future challenges for better water supply sustainability, Desalination. 309 (2013) 197-207. doi:10.1016/j.desal.2012.10.015. 
[22] A. Al-Karaghouli, L.L. Kazmerski, Energy consumption and water production cost of conventional and renewable-energy-powered desalination processes, Renewable and Sustainable Energy Reviews. 24 (2013) 343-356. doi:10.1016/j.rser.2012.12.064.

[23] L.F. Greenlee, D.F. Lawler, B.D. Freeman, B. Marrot, P. Moulin, Reverse osmosis desalination: Water sources, technology, and today's challenges, Water Research. 43 (2009) 2317-2348. doi:10.1016/j.watres.2009.03.010.

[24] M.A. Eltawil, Z. Zhengming, L. Yuan, A review of renewable energy technologies integrated with desalination systems, Renewable and Sustainable Energy Reviews. 13 (2009) 2245-2262. doi:10.1016/j.rser.2009.06.011.

[25] C. Sommariva, Desalination and advanced water treatment: economics and financing, Balaban Desalination Publ, Hopkinton, Mass, 2010.

[26] Global Water Intelligence (GWI), Desaldata, 2017. www.desaldata.com.

[27] A. Grübler, The rise and fall of infrastructures: dynamics of evolution and technological change in transport, Physica-Verlag, Heidelberg, 1990.

[28] A. Grübler, Technology and global change, Cambridge University Press, Cambridge (England) ; New York, N.Y, 1998.

[29] J.P. Martino, Technological forecasting for decision making, 2nd ed, North-Holland, New York, 1983.

[30] T. Modis, Strengths and weaknesses of S-curves, Technological Forecasting and Social Change. 74 (2007) 866-872. doi:10.1016/j.techfore.2007.04.005.

[31] D. Kucharavy, R. De Guio, Application of S-shaped curves, Procedia Engineering. 9 (2011) 559572. doi:10.1016/j.proeng.2011.03.142.

[32] C. Wilson, Meta-analysis of Unit and Industry Level Scaling Dynamics in Energy Technologies and Climate Change Mitigation Scenarios, (2009).

[33] A. Debecker, T. Modis, Determination of the uncertainties in S-curve logistic fits, Technological Forecasting and Social Change. 46 (1994) 153-173. doi:10.1016/0040-1625(94)90023-X.

[34] M. Arnaldos, Personal Communication, (2018).

[35] O.J. Morin, Design and operating comparison of MSF and MED systems, Desalination. 93 (1993) 69-109. doi:10.1016/0011-9164(93)80097-7.

[36] C. Frantz, B. Seifert, Thermal Analysis of a Multi Effect Distillation Plant Powered by a Solar Tower Plant, Energy Procedia. 69 (2015) 1928-1937. doi:10.1016/j.egypro.2015.03.190.

[37] L. Gao, S. Yoshikawa, Y. Iseri, S. Fujimori, S. Kanae, An Economic Assessment of the Global Potential for Seawater Desalination to 2050, Water. 9 (2017) 763. doi:10.3390/w9100763.

[38] N. Voutchkov, Energy use for membrane seawater desalination - current status and trends, Desalination. (2017). doi:10.1016/j.desal.2017.10.033.

[39] U. Caldera, C. Breyer, Learning Curve for Seawater Reverse Osmosis Desalination Plants: Capital Cost Trend of the Past, Present, and Future: LEARNING CURVE OF SWRO PLANT CAPEX, Water Resources Research. (2017). doi:10.1002/2017WR021402.

[40] G. Fiorenza, V.K. Sharma, G. Braccio, Techno-economic evaluation of a solar powered water desalination plant, Energy Conversion and Management. 44 (2003) 2217-2240. doi:10.1016/S01968904(02)00247-9.

[41] G.F. Nemet, Beyond the learning curve: factors influencing cost reductions in photovoltaics, Energy Policy. 34 (2006) 3218-3232. doi:10.1016/j.enpol.2005.06.020. 
379 [42] V.G. Gude, Desalination and sustainability - An appraisal and current perspective, Water Research. 38089 (2016) 87-106. doi:10.1016/j.watres.2015.11.012.

381 [43] D. Berry, Innovation and the price of wind energy in the US, Energy Policy. 37 (2009) 4493-4499. 382 doi:10.1016/j.enpol.2009.05.071.

383 [44] Y. Qiu, L.D. Anadon, The price of wind power in China during its expansion: Technology adoption, 384 learning-by-doing, economies of scale, and manufacturing localization, Energy Economics. 34 (2012) 772385 785. doi:10.1016/j.eneco.2011.06.008. 